\title{
Geir Uvsløkk, Jean Genet. Une écriture des perversions
}

\section{Stefano Genetti}

\section{OpenEdition}

\section{Journals}

\section{Edizione digitale}

URL: http://journals.openedition.org/studifrancesi/3859

DOI: 10.4000/studifrancesi.3859

ISSN: 2421-5856

\section{Editore}

Rosenberg \& Sellier

\section{Edizione cartacea}

Data di pubblicazione: 1 décembre 2012

Paginazione: 610

ISSN: 0039-2944

Notizia bibliografica digitale

Stefano Genetti, «Geir Uvsløkk, Jean Genet. Une écriture des perversions», Studi Francesi [Online], 168

(LVI | III) | 2012, online dal 30 novembre 2015, consultato il 07 mars 2021. URL: http://

journals.openedition.org/studifrancesi/3859; DOI: https://doi.org/10.4000/studifrancesi.3859

Questo documento è stato generato automaticamente il 7 mars 2021.

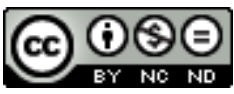

Studi Francesi è distribuita con Licenza Creative Commons Attribuzione - Non commerciale - Non opere derivate 4.0 Internazionale. 


\title{
Geir Uvsløkk, Jean Genet. Une écriture des perversions
}

\author{
Stefano Genetti
}

\section{NOTIZIA}

GEIR UVSLøKK, Jean Genet. Une écriture des perversions, Amsterdam, New York, Rodopi, 2011

(«Collection monographique Rodopi en littérature française contemporaine», 51),

pp. 235.

1 Non senza rinviare qui e là ad altri testi, l'A. della presente monografia si concentra sui racconti degli anni Quaranta, e segnatamente su Notre-Dame-des- Fleurs, Miracle de la rose e Journal du voleur, sottolineando la continuità tra la prima e la seconda fase dell'opera di Genet. Preferita a quella morale e statica di perversité, la nozione, più dinamica ed ereditata dalla psicopatologia, di perversion-cui vengono accostati termini quali aversion, conversion o interversion - consente allo studioso norvegese di sviluppare la propria tesi: il rivolgimento in Bene del Male - furto, omosessualità, tradimento implica in Genet una strategia complessa e obliqua dove alla provocazione, all'attacco frontale sferrato contro il lettore benpensante, si affianca la sovversione della logica dicotomica che la provocazione presuppone. Se il soggetto si definisce in opposizione alla norma, a essere problematizzata è tanto la norma imposta dalla mentalità dominante quanto la sua infrazione, a sua volta tradita, trasgredita. Radicali, le costanti oscillazioni e contaminazioni identitarie, etiche ed estetiche destabilizzano le distinzioni tra maschile e femminile, convenzione e deviazione, singolarità e universalità, e ciò su più piani: morale, sessuale e testuale. In base a queste tre categorie, correlate tra loro, il corpus viene analizzato facendo appello a una pluralità di strumenti di lettura, dall'estetica della ricezione alla teoria dei generi e dalla filosofia ai gender studies, da Barthes a Bourdieu e da Foucault a Judith Butler, nel corso di una trattazione sensibile alla trasformazione in leggenda del dato biografico. 
Intitolato Perversions morales, il primo capitolo, che si apre con uno sguardo critico sui saggi di Sartre e Bataille e si conclude con la contestazione delle posizioni di Éric Marty in merito al presunto antisemitismo di Genet, verte sia sulla celebrazione del crimine e sulla santificazione del criminale, sia sulla deviazione parodica della simbologia cattolica e sulla scandalosa ambivalenza del tradimento nel contesto di un'opera incentrata «sur le destin mortel d'une poignée de parias» (p. 41). Sono i condannati il cui corpo è fatto oggetto di una transubstanziazione mitica e mistica che ha per fulcro la morte: forma di opposizione al confluire di sacro e profano, essa fissa i contorni dell'eroe tragico votato a una solitudine dove rinuncia e libertà si sovrappongono e che è la condizione stessa della sua trasfigurazione letteraria. Il rovesciamento dei codici comportamentali fino alla rivendicazione dell'abiezione, della colpa e dell'infamia e la destabilizzazione dei confini tra i generi, l'inversione e la confusione dei ruoli fino alla dissoluzione dell'identità sessuale in un vertiginoso gioco di specchi sono i temi sviluppati nel secondo capitolo: Perversions sexuelles (si veda anche Jean Genet. Les revers $d u$ genre di agnès vanNouvong, Les Presses du réel, 2010). Paragonato a quello di Proust, Gide, Cocteau e Jouhandeau, l'atteggiamento ambiguo di Genet viene illustrato alla luce dei tagli imposti da Gallimard ad alcuni passi scabrosi: l'epurazione attuata dall'autore va ben oltre le aspettative dell'editore, e tuttavia sfugge a ogni univoca interpretazione autocensoria. Dai segmenti metadiscorsivi sul linguaggio e sulla poesia disseminati nei romanzi muove infine l'argomentazione nel terzo capitolo. Gli esibiti slittamenti tra vissuto e finzione e la frammentazione della continuità narrativa-l'A. insiste sull'influsso della tradizione secentesca e settecentesca degli ana sulla saga di Divine -, la disarticolazione sintattica e la predilezione per inversioni, iperbati e parentetiche, lo stile inteso come tono e canto e l'adozione dell'argot in quanto linguaggio della violenza, maschia, erotizzata e proscritta, o la teatralizzazione della parlata polisessuata dei travestiti sono altrettante Perversions textuelles. Queste sono indicative della sfida, della resistenza alle convenzioni e della demistificazione del linguaggio del potere, eroso e corrotto dall'interno, insite in una scrittura che associa sontuosità $\mathrm{e}$ profanazione e dove la poesia è concepita come punto di contatto e di collisione - si tratta di un incontro «au bord de la rupture», parafrasa l'A. (p. 183) - tra il visibile e l'invisibile, tra la parola e l'incomunicabile: è lì che si colloca l'insanabile, sublimata ferita che della scrittura di Genet costituisce il luminoso segreto. 